\title{
ARTICLE OPEN Global water policy and local payment choices in rural Africa
}

\author{
Rob Hope (iD ${ }^{1 *}$ and Paola Ballon ${ }^{1}$
}

Sub-Saharan Africa is least likely to meet the Sustainable Development Goal for safely-managed drinking water. Africa is estimated to require at least three times more annual investment, as a share of the gross regional product, than any other region to achieve 'basic' drinking water for everyone by 2030. If rural water users are to share some of these costs then the performance of current services needs to improve. In Africa, when a rural waterpoint fails, it takes a month or more to repair. We model water user choices across maintenance service models delivered by public, private and community providers with trade-offs in speed of repairing faults, payment levels and cash management. We find higher payments are associated with higher education and faster repair times. Household wealth, sex of respondent, seasonality, and waterpoint congestion, reliability and quality all influence payment choices. Understanding local payment choices provide behavioural clues to design more sustainable funding and service delivery models to align global and local drinking water goals.

npj Clean Water (2019)2:21 ; https://doi.org/10.1038/s41545-019-0045-y

\section{INTRODUCTION}

Despite the moral, economic and health imperative to provide everyone with safe drinking water every day, Africa has struggled to achieve or sustain global water policy goals. ${ }^{1-4}$ As we enter the third wave of global development goals (2015-2030) following the International Decade of Drinking Water and Sanitation (1980-1990) and the Millennium Development Goals (MDG, 2000-2015), it is expedient to reflect why billions of dollars of effort still leave over half the rural population of sub-Saharan Africa without basic drinking water, making the region by far the most underserved globally. ${ }^{1}$ Meeting the global MDG target for improved water access can largely be attributed to progress in China and India. ${ }^{5}$ Translating global water policy into meaningful change in rural Africa requires a closer examination of the water choices of the rural poor in three related domains, which can be achieved by (1) considering drinking water as a composite good with different attributes across service levels and management arrangements, (2) understanding behavioural responses to alternative management models; and (3) exploring the payment preferences of rural people to determine the extent to which costsharing is socially-acceptable.

Drinking water attributes encompassing the quality, quantity, reliability, proximity and affordability of the service are now acknowledged as both a global development goal and a human right. ${ }^{6}$ However, there is limited social choice mapping of these attributes. For example, the global goal is to achieve to safelymanaged drinking water on-demand, on-site and free of contamination for everyone by 2030. An estimated 2.1 billion people lack this service level including almost everyone in rural Africa. The second order, global goal is to achieve basic water access which is an 'improved service' with a return collection time of $30 \mathrm{~min}$ or less. Given the history of progress in rural Africa, achievement of even basic water services for everyone by 2030 would be an unprecedented policy success. Indeed, the off-site supply of improved water from handpumps and other infrastructure poses a collective action challenge in managing a point source used by multiple people for multiple purposes at different times of the year. ${ }^{7,8}$
The institutional arrangement that emerged in the 1980s, and has endured in rural Africa, is community-based management. ${ }^{9,10}$ It is a policy in which government and donors have funded the installation of infrastructure with the community responsible for funding ongoing operation and maintenance. The assumption is that communities wish to manage their water supplies and are capable of doing so effectively and equitably. These assumptions have been questioned widely. ${ }^{11-15}$ But what is the alternative? Urban water supplies in Africa have largely been managed by the public sector, sometimes with good performance, if regulated independently and monitored closely, but the majority are heavily subsidised and perform poorly. ${ }^{16}$ Performance-based models have recently emerged in rural water management with early evidence that they may be an alternative service provider in a more plural institutional arrangement between the state, market and community. ${ }^{17-20}$ These initiatives reflect renewed international development attention to support capacity to plan, finance and implement local solutions where government, private sector and communities can forge a commitment to greater self-reliance to deliver basic services for everyone. ${ }^{21}$ We explore this changing policy landscape from the perspective of rural water users.

\section{Policy design and water user choices}

What is unclear is the behavioural responses of rural people to alternative water supply attributes and institutional arrangements. Social choice theory suggests there will be competing preferences between attribute levels across water quality, reliability, affordability and proximity. Which matters most will likely vary by current water delivery performance, alternative water supplies, education, wealth, gender and the institutional arrangement. ${ }^{22,23}$ Do women prefer water quality more than reliability? Do water users have a preference between public, private or community management? Current policy is agnostic on such points providing a notionally 'improved water source' and assuming it will be managed with affordable tariffs and reliable performance. Increasing evidence disputes these assumptions but provides limited evidence as to whether investing more in a reliable service will elicit higher and more regular payments. Data from Ghana,

\footnotetext{
${ }^{1}$ School of Geography and the Environment and Smith School of Enterprise and the Environment, University of Oxford, Oxford, UK. *email: robert.hope@ouce.ox.ac.uk
} 
Kenya, Malawi, Rwanda and Zimbabwe indicate when a rural waterpoint fails it takes between 13 and 214 days to repair, with a modal value of around one month. ${ }^{11,15,24-27}$ A related measure of failure is downtime by functionality on the day of a visit. A study of 453,177 rural waterpoints in 38 African countries estimates an average of one in four waterpoints is not working at any one time. ${ }^{28}$ Given such long repair times carry high economic, social and health costs, particularly for women and girls, ${ }^{29}$ we focus our experiment on improvements in repair times to see how this affects payment behaviours.

Multi-country evidence across Africa indicates systemic late or non-payment for community waterpoints in rural areas. ${ }^{14,17,18,30}$ Which attributes of community water supply would elicit higher and better payment behaviours? Methodologically, there is a challenge in administering hypothetical, trade-off experiments orally to people with limited or no education or familiarity with such techniques. Here, we develop a pictorial format with careful explanation and test cards to allow water users to make their choices across competing alternatives or accept the current situation (status quo). Without improved understanding of what may incentivise user payments, public investments in infrastructure may provide limited financial returns and transient social impacts, which may partly explain the unsatisfactory progress achieved in rural water security in rural Africa to date.

A conceptual model summarises the discussion above and anticipates the choice modelling specification that follows (Fig. 1). We propose interactions between the payment behaviours of water users and the water services. This explicitly recognises the normative features of drinking water service levels for Sustainable Development Goal 6.1, and contextualises them by 'who' provides the service and 'why' people choose to pay, or not. Payment behaviours are shaped by the profile of users and their motives. Salient profile characteristics include the wealth, education attainment, and water demand of the household, as well as, the sex of the respondent. Water is considered a 'normal good' where higher wealth is likely to be associated with higher demand. Demand is related to both domestic (drinking, bathing, washing and laundry) and productive uses, particularly livestock watering from community water supplies in rural Africa. ${ }^{7,31}$ The sex of the respondent is of importance given the gendered roles and inequalities of water collection. For example, women in subSaharan Africa are six times more likely than men to have the burden of water collection duties. ${ }^{29}$ Motives to pay for improved drinking water explore user concerns across dimensions of cost, quality, accessibility, quantity, reliability, satisfaction with current service levels, and seasonal demand to recognise the influence of rainfall variation on demand. ${ }^{32}$ Water services are determined by the service provider and the level of service delivery. The latter are not homogenous but vary qualitatively and quantitatively by the quality, quantity, reliability, affordability and distance. Service provision policy has largely transferred responsibilities to communities, the response to which we explore through investigating user preferences to alternative models by local government or private sector.

\section{Tracing policy and practice from the 1980s}

The study site is Kwale county on the south coast of Kenya (Fig. 2). The location provides a unique historical context in the emergence and adoption of community-based management of handpumps in the 1980s, which has informed rural water policy across Africa and Asia until the present day. Further, the handpumps upon which most communities depend were installed in this period and were linked to training and support in village-level operation and management. The findings of the time indicate community adoption of this behavioural model to operate, finance and maintain handpumps used by community members. Thirty years on it is instructive to review the extent to which, and reasons why, water user choices still hold firm or have shifted to alternative or hybrid approaches. By examining the choice preferences of these communities we elicit insights into how and why behavioural norms may have shifted from their training and adoption of community operational, financial and management practices. Rural and remote, the county has high levels of poverty and a dependency on handpumps for domestic and productive water uses. ${ }^{27}$ While a bi-modal rainfall pattern provides an average of $1400 \mathrm{~mm}$ per year, extended dry spells lead to observed and sustained spikes in handpump usage as alternative water supplies become unavailable. ${ }^{32}$ A sample of 531 handpump locations was used as a sampling frame for a household survey administered in late 2013 and early $2014 .{ }^{30}$ At each of the 531 functional and non-functional handpumps, a stratified random sample of households provided 3500 households of which a random draw of 1560 households participated in the choice experiment.

The experimental design identifies four-choice attributes with varying levels (Fig. 3): (1) maintenance service provider (public, private), (2) guaranteed days for repairs $(2,4,6,8)$, (3) cash management (treasurer/cash, bank account, mobile money), (4) monthly household payment (USD $0.5,1.0,1.5,2.0$ ). The status quo option reflects community maintenance and the local payment arrangements, which are commonly cash. An orthogonal, main effects design generated 10 choice cards, each with two alternatives and a status quo option eliciting 10 choice responses. Attribute design emerged from examination of the literature including a study of over 25,000 handpumps in Liberia, Sierra Leone and Uganda concluding that "greater efforts are needed to test and evaluate alternative models for managing handpump water supplies". ${ }^{13}$ The modelling strategy has two stages. First, a conditional logit model (CLM) estimates the main attributes followed by interactions across four hypotheses of behavioural

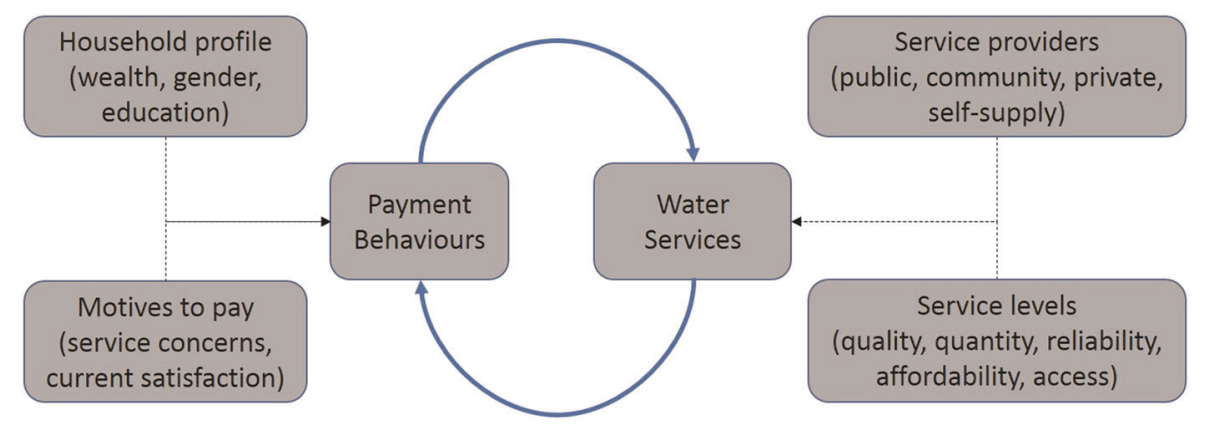

Fig. 1 Conceptual model of payment behaviours and drinking water services. Blue curved arrows: denote interactions between payment behaviours of water users and water services. Black straight arrows: denote factors shaping payment behaviours, and demand factors determining water services 

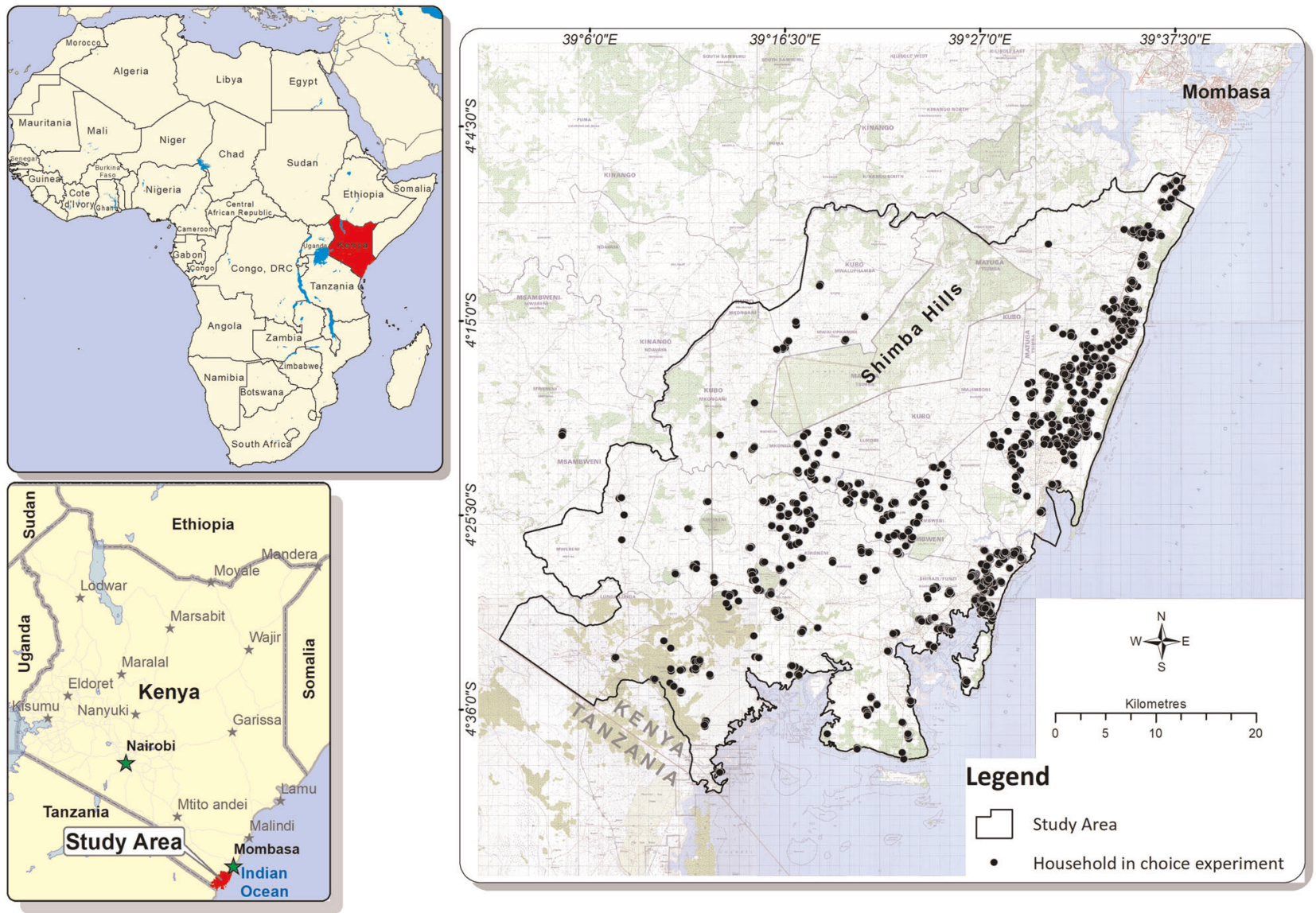

Fig. 2 Location of choice respondents in Kwale county, Kenya. Source: J. Katuva. The map illustrates locations of Kenya (upper left), the study site (lower left) and the households (right)

change: (a) multidimensional wealth, (b) education, (c) sex of respondent, and (d) household concerns. Second, a latent class model (LCM) specified by a discrete distribution of preferences to estimate heterogeneity following the assumption the variance in the error term is not constant but depends on individual observations. $^{33-36}$

\section{RESULTS}

Unpacking water use choices

Descriptive results indicate seven of ten households vote for the choice alternatives with the remainder preferring to continue with community management. Of the former, the majority require a repair service within four days (66\%), are willing to pay up to USD 1.0 per month (52\%) with a majority preference for payment (Fig. 4, left panel), and are split between cash management by banking $(38 \%)$ or mobile money (34\%) with preferences for private $(58 \%)$ or public (42\%) management. In contrast, households preferring community management are willing to accept repairs of more than eight days (55\%), do not want to pay (48\%) and are satisfied with a treasurer and cash storage (92\%). For the change group, reliability, distance and queuing (congestion) are the priority concerns with current satisfaction with maintenance services lower $(63 \%$ vs $74 \%)$ than the status quo group. While water quality, cost and seasonality have scores of lower concern $(<20 \%)$, seasonality is almost twice as important for those opting for change $(14 \%)$ than for those who prefer to stay with the current water-maintenance service (8\%). Plotting a cumulative density functions of the wealth index, the function of the status quo group lies always above the change group, indicating that the latter is better off (Fig. 4, right panel). We find no difference in voting preferences between men and women with the change group reporting slightly higher education attainment.

Results from the CLM indicate a general pattern of disutility from slower repairs, higher repair payments and use of mobile payments, and of positive utility from external maintenance provision from public or private suppliers (Table 1). The LCM reveals preference heterogeneity between the probability of being a member of Class 1 (45\%) or Class 2 (55\%). As explained in the methods section, each latent class is inferred from the levels of the attributes through multinomial logistic regression. Class 1 has increasing negative utility as repair times and payment levels increase. In contrast, Class 2 has positive utility from repairs within four days or a payment of up to USD 1.0 per month. Both classes prefer external maintenance providers with a slightly higher preference for public provision. Cash management preferences are negative but non-significant for Class 1 whilst Class 2 has a positive preference for a bank.

We start by assessing the interaction of choice attributes with the profile of household by wealth, education and the sex of respondent. Higher wealth is positively associated with a preference for faster repairs and either public or private management, as opposed to, the status quo for both classes. Higher wealth and payment also have a positive effect but only for Class 1; Class 2 has a negative and significant effect. Higher education in Class 1 is positively and significantly associated with preference for faster repairs, higher payments, and either public or private management. In contrast, higher education in Class 2 is associated with rejection of public or private management, but is still positively associated with preference for higher payments. Female 


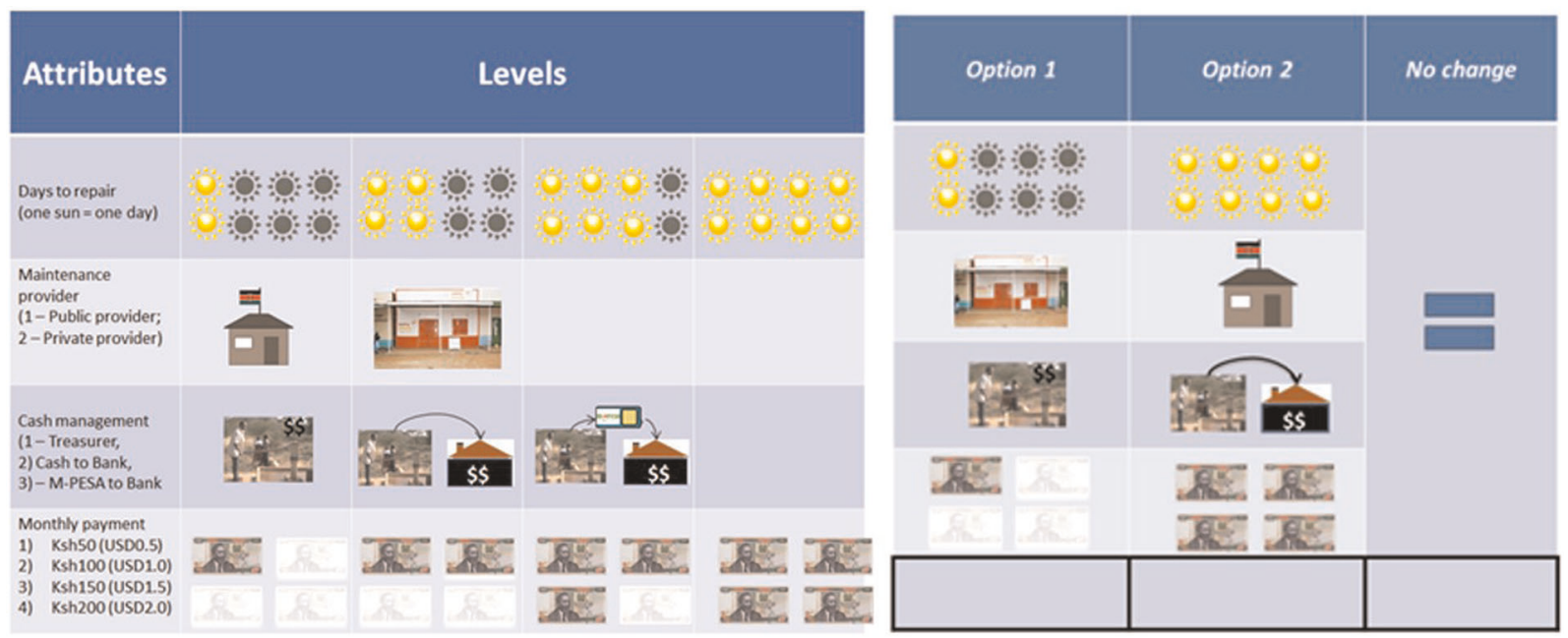

Fig. 3 Pictorial design of choice attribute levels (left panel) and test choice card (right panel). The left panel presents the attributes and levels of the choice experiment, while the right panel illustrates three options for the pilot choice card, including two alternatives (option 1, option 2) and 'no change', which reflects the existing community management

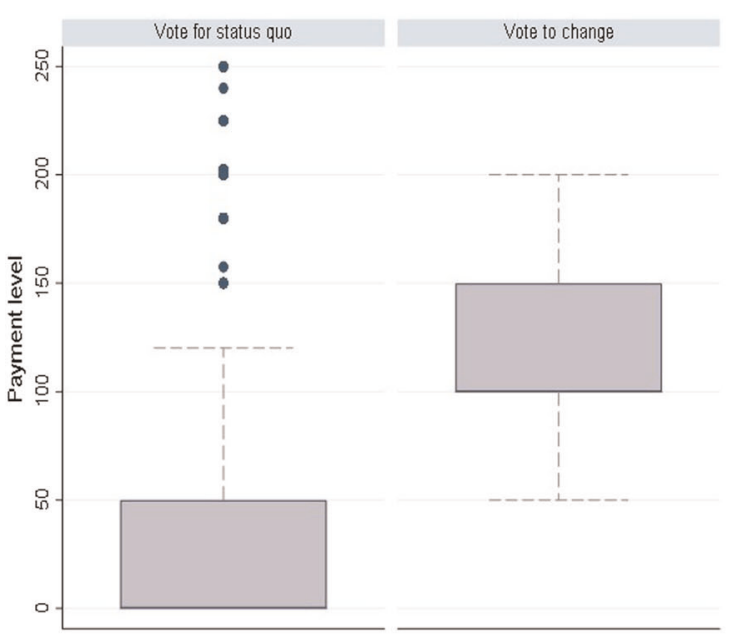

Box -plots of payment levels by type of voter

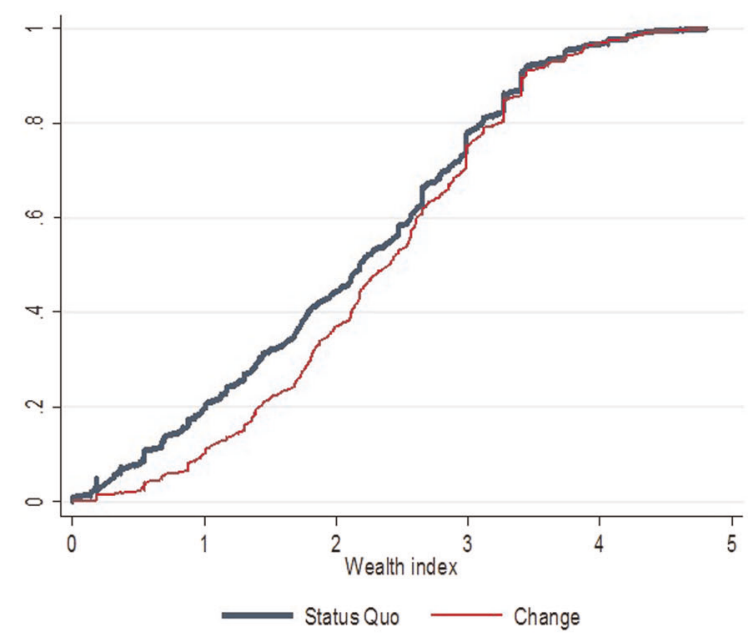

Wealth index cumulative density function, by type of voter

Fig. 4 Alternative payment preferences disaggregated by wealth quintiles. Box-plot legend. Centre line: denotes the median; bounds of the box: denote the 25th percentile (lower hinge) and the 75th percentile (upper hinge); whiskers: denote the lowest (lower whisker) and highest observations (upper whisker), respectively. Cumulative density functions legend. Blue thick line: denotes the cumulative density function of wealth (index) for status quo voters; red line: denotes the cumulative density function of wealth (index) for voters opting for change

respondents in Class 1 have a positive association with faster repairs and either public or private management, but reject higher payments. In contrast, women in Class 2 will pay more but reject public or private management. In summary, faster repairs provide a positive and significant utility with higher wealth and education. Preferences then split with Class 1 preferring public or private management, which Class 2 rejects. Higher payment is positively associated with higher education, but splits the two classes by wealth and sex of respondent. The findings indicate increasing education and wealth in a household are positively associated with faster repairs and willingness to pay for the service.

Next we turn to household motives across our seven categories (Fig. 5). If a household is satisfied with the current maintenance system, they have a positive and significant association with more repair days and not paying, but reject public or private management. This pattern reflects Class 1, with the reverse pattern for Class 2. This is intuitive in that if a community is currently providing a good service, households may have little reason to shift in the short term. Considering household concerns over seasonal variability, which are related to periods of drought, we again see an expected pattern where concerns are positively associated with preference for faster repairs and payment for Class 1. The results are less clear for Class 2, though there is significant and negative utility with paying even with seasonality concern.

In Class 1, households concerned with handpump reliability gain positive utility from faster repairs and public or private management, but negative utility from increasing payments. For Class 2, the same concern for households has positive utility from increasing payments, but with rejection of both public or private management. Where distance is a concern, neither class wishes to pay, with Class 1 preferring public or private management and Class 2 rejecting both. Concerns with queuing at handpumps provide the one example where households in both classes gain positive utility from public or private management. Classes 1 and 2 households differ, with the former gaining utility from faster repairs and paying, and the latter following the reverse pattern. Households belonging to Class 1 exhibiting concerns for water quality gain utility from faster repairs, but the same group have no 


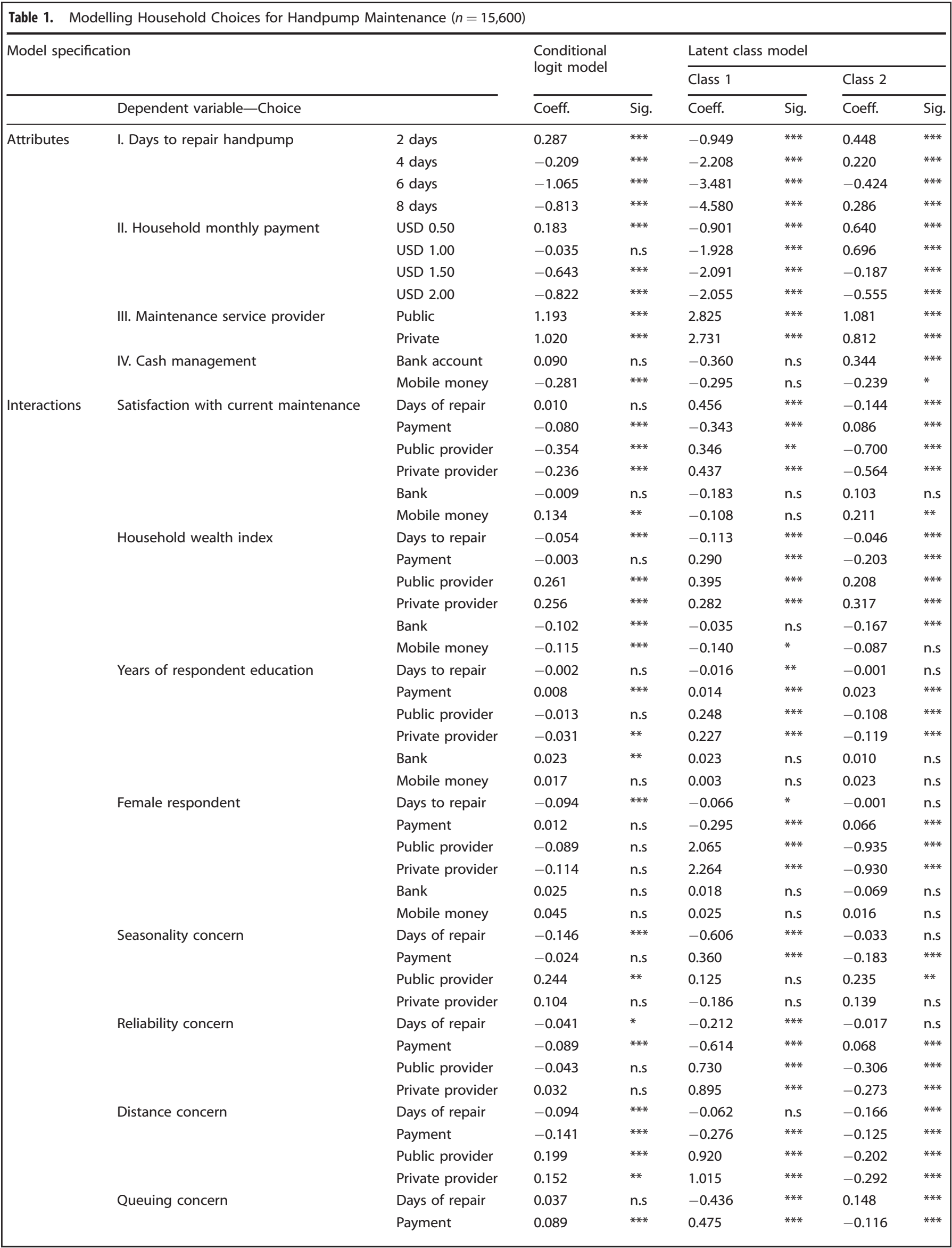




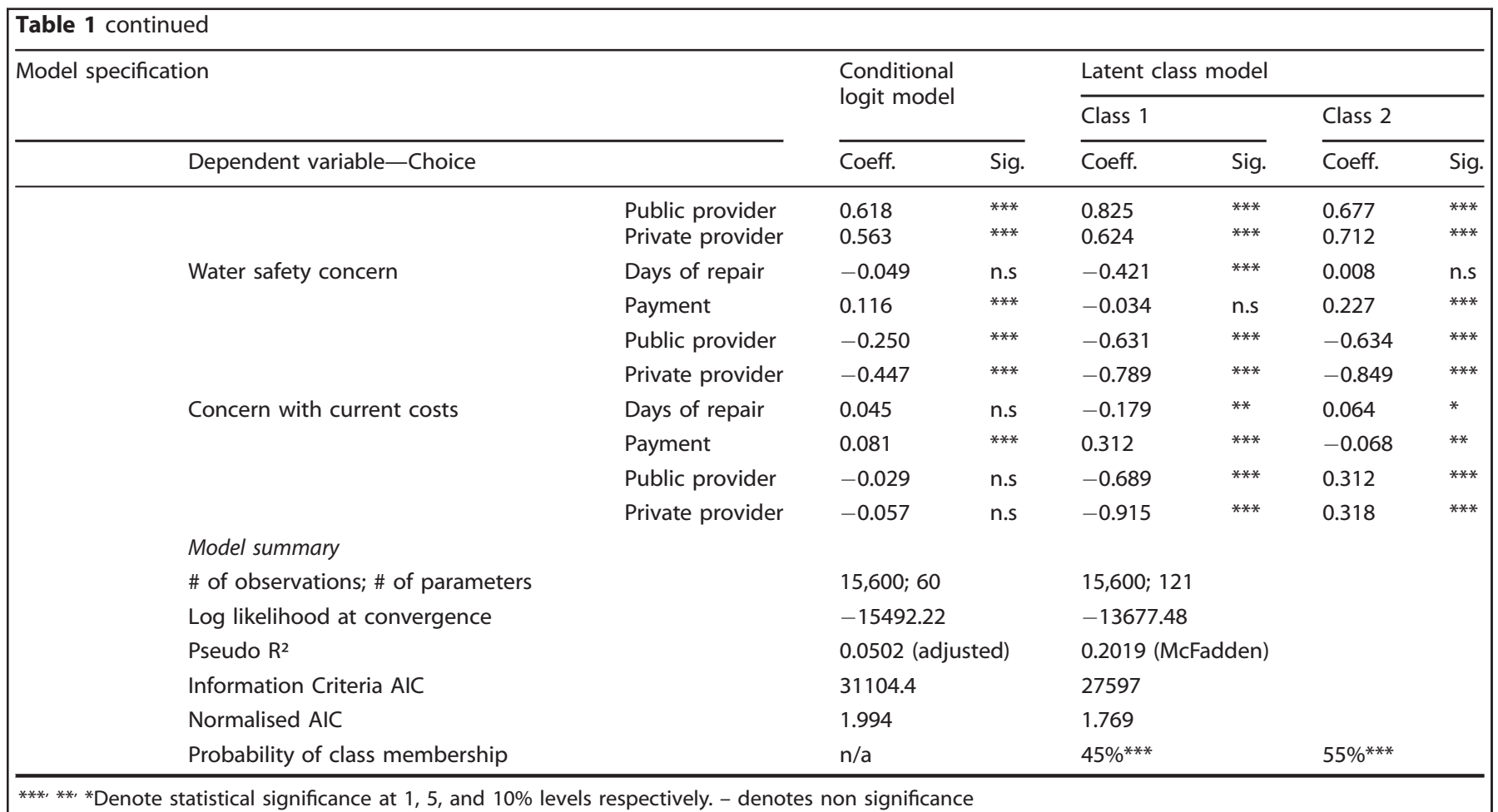

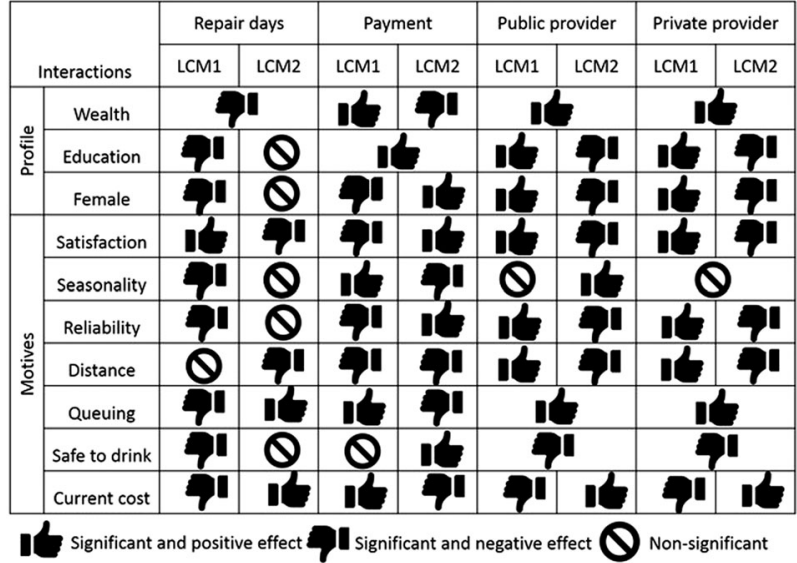

Fig. 5 Summary of the latent class model results by household profile and motives. The thumbs up (down) emoji denote a positive (negative) and statistically significant coefficient in the latent class model. The prohibited emoji denotes a not statistically significant coefficient

significant result for payment. Households in both classes reject public or private management if concerned by water quality. Finally, households concerned with current costs of services have a preference for faster repairs and payment though without support for public or private management. For Class 2, households concerned with current costs result in negative utility from increasing payments, and a positive preference for public or private management.

\section{DISCUSSION}

Behavioural clues to unlock user payments

Our results reveal behavioural clues as to why investments in community waterpoints remain an enduring development challenge in rural Africa. Choice heterogeneity specified across service levels by different management arrangements illustrate the significant variation in demand for faster repairs to community water supplies. Provision of a unitary service level does not meet the varying preferences of household water users. Education, wealth and gender moderate choices with all three positively associated with utility gains from faster repairs for Class 1, but only wealth positively influencing preference for faster repair for Class 2. Payment choices are positively shaped by wealth and education for Class 1, and education and sex of respondent for Class 2. Increasing education appears a critical and cross-cutting priority in nudging welfare-enhancing behaviour, which builds on wider literature on how public investments in rural water infrastructure may bypass the poor without ancillary investments in education, particularly for women. ${ }^{37}$

Women's choices are not uniform but diverge across the two classes challenging simple assumptions of preference homogeneity. Of note are the payment preferences of women in Class 2 who will pay but do not gain utility from faster repairs, or public or private management. It is an unexpected result that women who often have most to lose from non-functioning water infrastructure appear to gain no utility from faster repairs. It is plausible that Class 2 women have lower education compared to Class 1 women, and align more to the status quo group, given negative utility associated with public or private management. However, there is the separate but important finding which distinguishes Class 2 in their specific concern with water quality, which is positively associated with payments. While the crude classification of 'water quality' is not qualified by the bacteriological, chemical or aesthetic issues influencing this concern, or by our knowledge of the extent and severity of the disease burden in the household, the fact that this motivation influences payment for this majority class holds potential traction in improving the regulatory and monitoring frameworks for rural drinking water. If water users view water quality as a priority concern, this may unlock payment behaviours to encourage water safety plans and monitoring systems, to create certainty and value for users, and leverage cost- 
sharing arrangements between public investments and private interests.

Cost-sharing arrangements will require improved, community financial management, particularly the collection and safe storage of water payments. This poses related questions on the acceptability of more transparent and lower transaction cost financial systems, such as mobile money or banking, which gain limited support from this experiment. The political economy of managing 'cash' in rural communities is often opaque, and communities often struggle with cash management when failure events for waterpoints occur, resulting in delays of weeks or months before communities can agree how to replace 'lost' money to pay for repairs. ${ }^{10,13,14,17}$ While the descriptive results indicate a high proportion of users voting for change, supportive of more accountable banking or mobile money approaches, the modelling results are less optimistic. Class 2 members do associate positive utility with banking of water payments but, like Class 1, they reject mobile money. Given the sensitive nature of managing money in rural communities, it is not surprising to see caution in leaping to a solution without more knowledge and assurances. However, the result signals this is likely to be a non-trivial exercise, with wider work of observed payment records in the study site illustrating systemic late, or non-payment within communities distinguished by multi-decadal, water payment collection. ${ }^{30}$

The motivations for households to pay for faster repair services centre on concerns with seasonality, current costs and handpump congestion (queuing time) for Class 1, and water quality and reliability for Class 2. Shorter distance to the handpump and increased reliability, may create utility but do not unlock payments for Class 1. Where there is dissatisfaction with current management this also elicits positive payment behaviours. With alternative water supplies from surface water during wetter periods, there is less dependency on groundwater until drought events occur. This also relates to the concern with congestion as strategic waterpoints then face peak demand. It is noteworthy that distance and reliability are not significant, though one may consider congestion as a sub-set of reliability. If the handpump is not working then congestion effects are likely to increase.

The third significant motivation is concern with current costs, which touches on the importance of global monitoring affordability as a normative indicator of the human right to water., Community management of rural handpumps is largely unregulated in Kenya, and most of Africa, and pricing is a local matter with evidence that community handpumps often become semiprivatised to become a 'club good' with a variety of membership arrangements, which may exclude some users. ${ }^{16}$ Following Class 2 's positive association of utility with banking, their concern with current costs is negatively associated with payments, but positively associated with public or private management. This is the one of three concerns where Class 2 gains utility from noncommunity management, and suggests where current costs are unreasonable, and thus wider support may be justified and welcome. In contrast, Class 1's concerns with costs gain utility from payments but reject public or private management. This suggests users have distinct preferences for financial roles and responsibilities between community and external partners, and the associated requirement to negotiate an acceptable approach over time.

Water quality is the one significant motivation for payment by Class 2. Like affordability, global monitoring struggles to make progress on robust water quality metrics in rural areas. ${ }^{1,4}$ This partly reflects the distinct methodological and operational challenge of generating accurate data given current methods and levels of investment. Testing for bacteria, viruses, or harmful chemicals, such as arsenic or fluoride, require capacity, resources and data quality assurance which is challenging using both current and emerging techniques. The finding that users identifying water quality concerns reject public or private management is instructive given the significant technical challenges of monitoring quality. This requires further investigation.

Global policy as risk allocation and value creation

Slow and uneven progress for drinking water service delivery in rural Africa demands new thinking to design alternative institutional models to unlock payment behaviours for faster repairs in days rather than weeks. Households choosing community management in rural Kenya accept or are resigned to lower levels of service performance with reluctance or inability to pay. This does not create a binary division between private and public ideologies of service delivery. It focuses attention on how to fairly and effectively allocate operational and financial risks aligned to public policy goals, recognising communities will play a central role in any sustainable institutional model. Unlocking user payment behaviours is foundational to attract alternative forms of sustainable finance and reinforce the primacy of delivering high quality services which create value for people with often limited and variable income. Delivering reliable drinking water services of good quality, at waterpoints without long queues and in times of drought are contextual attributes to improve water payment behaviours to meet and sustain global policy goals.

\section{METHODS}

Experimental design and analysis

Unlike text-based, choice cards, we chose to use images to represent the attributes under investigation to promote inclusive participation, particularly women in households as they commonly are responsible for water collection and management. A careful process of designing and testing the cards led to a final format to represent: (a) number of days to repair the handpump, (b) maintenance service provider, (c) cash management system and (d) level of household monthly payment. Days to repair was represented by a sun and spanned 2, 4, 6 or 8 days. The range reflected wider analysis and an improvement on the current average of a month to repair broken handpumps. ${ }^{13}$ The maintenance service provider introduced public and private providers with the status quo reflecting the community management model common across Kenya and Africa. Cash management included storing payments in a bank, which has been recommended since the late 1980s, and the increasing prevalence of mobile money systems in Kenya. Mobile money is a technology to transfer, receive and store money using a mobile phone. Globally, there are 866 million users processing USD 1.3 billion per day. ${ }^{38}$ The technology has increased access for unbanked people in rural Africa and Asia where traditional banks and banking systems have failed to reach or benefit poor people. The status quo reflects the common situation of the water committee, through the treasurer or Chair, holding the cash. Monthly payments considered current payment levels and seasonal variability to centre on a range from USD 0.50 to USD 2.00 per household per month. Kenyan Shilling notes in denominations of 50 were used to represent these values with the exchange rate (KES $100=$ USD 1.0, 2013). The test (dummy) card below illustrates the application which ran smoothly in the field (Fig. 3).

The attributes followed a main effects design with 10 choice cards per household to elicit 15,600 observations with two choice alternatives and the status quo per observation $(n=46,800)$.

\section{Data collection}

In 2013, a water point survey identified 574 handpumps of which $45 \%$ were non-functioning on the day. Excluding locations where handpumps were abandoned, a sample of 531 handpump locations was used as a sampling frame for a household survey administered from October 2013 to February 2014. At each of the 531 handpumps, a stratified random sample of households from transect walks in roughly cardinal pathways of up to $2 \mathrm{~km}$ away from the handpump generated a sample of 3500 households. A pilot survey was conducted with 19 enumerators recruited from communities across the study area who administered the survey in local languages (Swahili, 54\%; Digo, 43\%; Duruma, 2\%; other, 1\%). The main survey provided an introduction including ethics and informed consent, then sections on household demographic, socio-economic, water behaviours, welfare and concerns. All respondents were adults ( $>18$ years) and generally the 'mother' or 'father' in the household. Where a household was 
unavailable, one return trip would be made and if no one was available, a random replacement near the household would be selected. The choice experiment was administered as a random draw of roughly half of the full sample. This included a structured explanation with laminated cards for the 'test card' and the 10 choice cards. Data were collected on tablets using doforms software (www.doforms.com), uploaded to a server each evening by the field teams supported by University of Oxford staff for local and remote analysis to allow guidance to the enumerators on a daily basis.

Ethical permission for the experiment was provided by the Central University Research Ethics Committee (CUREC) at the University of Oxford and a research permit from the Government of Kenya's National Council for Science and Technology.

\section{Econometric modelling}

Following this analytical approach, the econometric specification considers two types of models: a CLM and a LCM. In the CLM, an individual is assumed to have preferences defined over a set of unordered alternatives indexed by $1,2, \ldots, J$. Let $y_{i j}$ be an indicator variable for the alternative actually chosen by the $i$-th individual, that is, $y_{i j}=1$ if individual $i$ chose alternative $j$ and 0 otherwise. The exogenous variables in this type of specifications are of two types: alternative specific, denoted by $x$ and individual specific, denoted by $z$. Alternative-specific variables $x_{i j}$ vary among the alternatives (as well as among individuals), reflecting the attribute levels of each option. Individual-specific variables $z_{i}$ vary only among individuals and provide information on the socio-economic profile of each person. While modelling these effects is often useful when the aim is to assess general profiles, our interest here is in the interaction between individual characteristics and attribute levels. These interactions provide a more comprehensive assessment of the effect of profile characteristics on the choice mode. Assuming we have $p$ alternative-specific variables, and $q$ individual-specific ones our random-utility model can then be expressed as:

$$
U_{i j}=\boldsymbol{\beta}^{T} \mathbf{x}_{i j}+\boldsymbol{\Gamma}^{T} \mathbf{w}_{i j}+\varepsilon_{i j}
$$

where $U_{i j}$ denotes the utility of the $i$-th individual associated with option $j$; $\boldsymbol{\beta}$ and $\mathbf{x}_{i j}$ are $p \times 1$ vectors of alternative-specific regression coefficients and variables, respectively. The interaction effects between alternative-specific variables and individual-specific ones is represented by the matrix $\widetilde{\mathbf{W}}_{i j}$ of size $p \times q$, with typical element $\left[x_{i j k} \times z_{l}\right]$ for $k=1, \ldots, p$ and $I=1, \ldots, q$. As Eq. (1) is a scalar, we vectorise the matrix $\widetilde{\mathbf{W}}_{i j}$ using the $\operatorname{vec}(\cdot)$ operator leading to a vector of interaction effects $\mathbf{w}_{i j}=\operatorname{vec}\left[\widetilde{\mathbf{W}}_{i j}\right]$ of size $p q \times 1$, and to an associated vector of regression coefficients $\Gamma$ of size $p q \times 1$.

The disturbances $\varepsilon_{i j}$ in this framework denote individual heterogeneity and are assumed to be independently and identically distributed (IID) with the same Type I extreme value distribution:

$F\left(\varepsilon_{i j}\right)=\exp \left[-\exp \left[-\varepsilon_{i j}\right]\right]$.

Under these assumptions the probability that individual $i$ choses alternative $j$ is:

$\operatorname{Prob}\left[U_{i j}>U_{i m}\right]$ for all $m \neq j$,

and it has been shown ${ }^{39}$ that for independent extreme value (Gambel) distributions, as in (2) above, this probability is:

$$
\pi_{i j}=\operatorname{Prob}\left[y_{i m}=j\right] \frac{\exp \left[\boldsymbol{\beta}^{T} \mathbf{x}_{i j}+\boldsymbol{\Gamma}^{T} \mathbf{w}_{i j}\right]}{\sum_{m=1}^{J} \exp \left[\boldsymbol{\beta}^{T} \mathbf{x}_{i m}+\mathbf{\Gamma}^{T} \mathbf{w}_{i m}\right]}
$$

where $y_{i m}$ is the index of the choice made. The model defined by (3) is estimated through Maximum Likelihood. ${ }^{40}$ Note that the IID assumptions made about $\varepsilon_{i j}$ are quite stringent and induce the 'Independence from Irrelevant Alternatives' or IIA property that is inherent to the CLM.

To overcome the limitation imposed by the IIA property we specify a LCM. This model accounts for parameter heterogeneity across individuals through a discrete distribution or set of classes unknown to the researcher. Estimates consist of the class specific parameters and for each individual, a set of probabilities defined over the classes. Within the class, choice probabilities are assumed to be generated by a multinomial logit model. For a given individual, the model's estimate of the probability of a specific choice is the expected value (over classes) of the class-specific probabilities. ${ }^{39}$

The latent class specification following the matrix design presented above, determines in our case a two-class model as the preferred option. With a normalised AIC criterion of 1.769 this specification leads to an improvement in pseudo- $\mathrm{R}^{2}$ from 0.05 (CLM) to 0.20 (LCM). Two classes were specified with a 45 per cent and 55 per cent likelihood of selection (Class 1 and Class 2, respectively).

Version 5 of the NLOGIT software ${ }^{40}$ modelled the conditional logit and latent class specifications. Descriptive analysis was run in Excel, SPSS and STATA 14.

\section{DATA AVAILABILITY}

Anonymised survey data are available here: http://reshare.ukdataservice.ac.uk/ 853912/.

\section{CODE AVAILABILITY}

Econometric code is available here: http://reshare.ukdataservice.ac.uk/853912/.

Received: 24 May 2019; Accepted: 9 September 2019;

Published online: 05 November 2019

\section{REFERENCES}

1. UNICEF/WHO. Safely managed drinking water - thematic report on drinking water. (World Health Organisation, Geneva, Switzerland, 2017).

2. Hutton, G. \& Varughese, M. The Costs of Meeting the 2030 Sustainable Development Goal Targets on Drinking Water, Sanitation, and Hygiene. (Water and Sanitation Program (WSP) World Bank, Washington, D.C., 2016).

3. UNGA. Resolution adopted by the General Assembly on 28 July 2010-The human right to safe drinking water and sanitation. A/RES/64/292 (Office of the United Nations High Commissioner for Human Rights. (OHCHR, Geneva, Switzerland, 2010).

4. Prüss-Ustün, A. et al. Burden of disease from inadequate water, sanitation and hygiene in low- and middle-income settings: a retrospective analysis of data from 145 countries. Trop. Med. Int. Health 19, 894-905 (2014).

5. Fukuda, S., Noda, K. \& Oki, T. How global drinking water targets were developed and achieved. Nat. Sust. 2, 429-434 (2019).

6. Langford, M. \& Russell, A. The human right to water: theory, practice and prospects. (Cambridge University Press, Cambridge, 2017).

7. Elliott, M. et al. Addressing how multiple household water sources and uses build water resilience and support sustainable development. npj Clean. Water 2, 6 (2019).

8. Hope, R. \& Rouse, M. Risks and responses to universal drinking water security. Philos. T. R. Soc. A 371, 1-23 (2013).

9. Arlosoroff, S. et al. Community Water Supply: The Handpump Option. (The World Bank, Washington D.C., 1987).

10. Narayan, D. The contribution of people's participation: evidence from 121 rural water supply projects. Environmentally Sustainable Development occasional paper series: No. 1. (The World Bank, Washington D.C., 1995).

11. Chowns, E. Is community management an efficient and effective model of public service delivery? Lessons from the rural water supply sector in Malawi. Public Admin. Dev. 35, 263-276 (2015).

12. Cleaver, F. Paradoxes of participation: Questioning participatory approaches to development. J. Int. Dev. 11, 597-612 (1999).

13. Foster, T. Predictors of sustainability for community-managed handpumps in sub-Saharan Africa: evidence from Liberia, Sierra Leone, and Uganda. Environ. Sci. Technol. 47, 12037-12046 (2013).

14. Harvey, P. \& Reed, R. Community-managed water supplies in Africa: sustainable or dispensable? Community Dev. J. 42, 365-378 (2006).

15. Hope, R. Is community water management the community's choice? Implications for water and development policy in Africa. Water Policy 17, 664-678 (2015).

16. Banerjee, S. G. \& Morella, E. Africa's Water and Sanitation Infrastructure: Access, Affordability, and Alternatives. (World Bank, Washington D.C., 2011).

17. Koehler, J., Thomson, P. \& Hope, R. Pump-Priming Payments for Sustainable Water Services in Rural Africa. World Dev. 74, 397-411 (2015).

18. Davis, J. Private-sector Participation in the Water and Sanitation Sector. Annu. Rev. Env. Resour. 30, 1-39 (2005).

19. Narkevic, J. \& Kleemeier, E. A global review of private operator experiences in rural areas. Private Operator Models for Community Water Supply. Rural Water Supply Series Field Note (February 2010). (World Bank Water and Sanitation Program, Nairobi, 2010).

20. Koehler, J., Rayner, S., Katuva, J., Thomson, P. \& Hope, R. A cultural theory of drinking water risks, values and institutional change. Glob. Environ. Chang. 50, 268-277 (2018)

21. McNicholl, D. et al. Performance-based funding for rural water services in Africa. Uptime consortium, Working Paper 1, https://www.smithschool.ox.ac.uk/ research/water/report-performance-basedfunding.html (2019). 
22. USAID. USAID Policy Framework: Ending the need for Foreign Assistance. US Agency for International Development, Washington, D.C., https://www.usaid.gov/sites/ default/files/documents/1870/WEB_PF_Full_Report_FINAL_10Apr2019.pdf (2019).

23. World Bank. The demand for water in rural areas: determinants and policy implications. World Bank Res. Obser. 8, 47-70 (1993).

24. Whittington, D. et al. How well is the demand-driven, community management model for rural water supply systems doing? Evidence from Bolivia, Peru and Ghana. Water Policy 11, 696-718 (2009).

25. Hoko, Z., Demberere, T. \& Siwadi, J. An evaluation of the sustainability of a water supply project in Mt. Darwin, Zimbabwe. J. Sust. Dev. Africa 11, 98-112 (2009).

26. Nagel, C., Beach, J., Iribagiza, C. \& Thomas, E. Evaluating cellular instrumentation on rural handpumps to improve service delivery - a longitudinal study in rural Rwanda. Environ. Sci. Technol. 49, 14292-14300 (2015).

27. Foster, T. \& Hope, R. Evaluating waterpoint sustainability and access implications of revenue collection approaches in rural Kenya. Water Resour. Res. 53, 1473-1490 (2017)

28. Foster, T., Furey, S., Banks, B. \& Willetts, J. Functionality of handpump water supplies: a review of data from sub-Saharan Africa and the Asia-Pacific region. J. Int. Water. Res. Devt. https://doi.org/10.1080/07900627.2018.1543117

29. UNDESA. Environment. The World's Women 2015: Trends and Statistics. (United Nations Department of Economic and Social Affairs, Statistics Division, New York, 2015).

30. Foster, T. \& Hope, R. A multi-decadal and social-ecological systems analysis of community waterpoint payment behaviours in rural Kenya. J. Rural. Stud. 47, 85-96 (2016)

31. White, G. F., Bradley, D. J. \& White, A. U. Drawers of Water: Domestic Water Use in East Africa. (University of Chicago Press, Chicago, 1972).

32. Thomson, P. et al. Rainfall and groundwater use in rural Kenya. Sci. Total Environ 649, 722-730 (2019).

33. Boxall, P. C. \& Adamowicz, W. L. Understanding heterogeneous preferences in random utility models: a latent class approach. Environ. Resour. Econ. 23, 421-446 (2002).

34. McFadden, D. Conditional logit analysis of qualitative choice behavior. In Frontiers in Econometrics (ed Zarembka, P.) 105-142 (Academic Press, New York, 1974).

35. McFadden, D. Econometric models of probabilistic choice. In: Structural Analysis of Discrete Data with Econometric Applications (eds Manski, C. and McFadden, D.) 198-272 (MIT Press, Cambridge, 1981).

36. Swait, J. A structural equation model of latent segmentation and product choice for cross-sectional revealed preference choice data. J. Retail. Consum. Serv. 1, 77-89 (1994).

37. Jalan, J. \& Ravallion, M. Does piped water reduce diarrhea for children in India? Econometrica 112, 153-173 (2003).

38. GSMA. State of the Industry Report on Mobile Money 2018. GSM Association, London (2019) https://www.gsma.com/r/wp-content/uploads/2019/05/GSMAState-of-the-Industry-Report-on-Mobile-Money-2018-1.pdf.

39. Maddala, G. S. Chapter 3: Probabilistic-choice models. In: Limited-dependent and qualitative variables in econometrics. 59-78 (Cambridge University Press, Cambridge, 1983).

40. Greene, W. H. NLOGIT version 5 user guide. (Econometric Software, Plainview, New York, USA, 2012).

\section{ACKNOWLEDGEMENTS}

This paper is an output from the "New Mobile Citizens and Waterpoint Sustainability in Rural Africa" (ESRC Project ES/J018120/1) and "Groundwater Risk Management for Growth and Development" NERC Project NE/M008894/1) supported by the U.K. Economic and Social Research Council (ESRC) and the U.K. Department for International Development (DFID). The authors thank N. Gladstone, J. Katuva, T. Foster, S. Goodall J. Koehler, P. Thomson, Rural Focus Ltd., the County Government of Kwale and participants. The funders had no role in study design, data collection and analysis, decision to publish or preparation of the manuscript.

\section{AUTHOR CONTRIBUTIONS}

R.H. developed the research ideas and designed the choice experiment. P.B. and R.H. conducted the modelling and data analysis. R.H. and P.B. wrote the manuscript.

\section{COMPETING INTERESTS}

The authors declare no competing interests.

\section{ADDITIONAL INFORMATION}

Correspondence and requests for materials should be addressed to R.H.

Reprints and permission information is available at http://www.nature.com/ reprints

Publisher's note Springer Nature remains neutral with regard to jurisdictional claims in published maps and institutional affiliations.

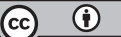

Open Access This article is licensed under a Creative Commons Attribution 4.0 International License, which permits use, sharing, adaptation, distribution and reproduction in any medium or format, as long as you give appropriate credit to the original author(s) and the source, provide a link to the Creative Commons license, and indicate if changes were made. The images or other third party material in this article are included in the article's Creative Commons license, unless indicated otherwise in a credit line to the material. If material is not included in the article's Creative Commons license and your intended use is not permitted by statutory regulation or exceeds the permitted use, you will need to obtain permission directly from the copyright holder. To view a copy of this license, visit http://creativecommons. org/licenses/by/4.0/.

(c) The Author(s) 2019 